\title{
Overview of Bone Morphogenetic Proteins
}

\author{
John M. Wozney, PhD
}

Study Design. A literature review was conducted.

Objectives. To review the discovery of the bone morphogenetic proteins and describe the bone morphogenetic protein products that will or may be available for clinical use.

Summary of Background Data. Bone morphogenetic proteins comprise the osteoinductive component of several tissue engineering products in late-stage development as replacements for autogenous bone graft, and for bone augmentation and repair.

Methods. The literature on bone morphogenetic proteins was reviewed.

Results. Bone morphogenetic proteins were discovered originally on the basis of their presence in osteoinductive extracts of bone matrix. Molecular cloning of bone morphogenetic proteins demonstrated that they are a family of related differentiation factors, each capable of inducing the formation of new bone tissue when implanted. Two of the molecules in clinical use, recombinant human bone morphogenetic protein-2 and recombinant human bone morphogenetic protein-7 (OP-1) are produced in a biotechnology process using recombinant deoxyribonucleic acid technology that offers unlimited supply and substantial control over purity and reproducible activity. A third material, bovine bone morphogenetic protein extract, is extracted from bone, and contains a mixture of bone morphogenetic protein molecules. Each of these molecules, although osteoinductive in vivo, has different physiologic roles and biologic activities in vivo and in vitro. Successful development of a product for use in spinal fusion involves selecting the osteoinductive molecule, the amount of the bone morphogenetic protein required, and the method of delivery, as well as conducting subsequent preclinical and clinical studies to evaluate its efficacy and safety.

Conclusions. On the basis of the data provided in this issue of Spine, some of these bone morphogenetic protein-based products provide for revolutionary therapies in orthopedic practice. [Key words: bone graft, bone morphogenetic protein, osteoinduction] Spine 2002;27:S2-S8

A variety of graft materials are used to augment bone and bone healing. The relative success of these materials depends on many factors including the surgical application and technique as well as properties of the graft itself. In addition to their physical properties, grafts may provide osteoconductive or osteoinductive activities. Osteocon-

From Wyeth Research, Cambridge, Massachusetts.

Device Status/Drug Statement: The devices and drugs described in this article are being evaluated as part of an ongoing FDA-approved investigational protocol (IDE) for XXXX. The devices and drugs in this article that are not FDA-approved for this indication are not commercially available in the United States.

Conflict of Interest: No funds were received in support of this work. One or more of the authors have received or will receive benefits for personal or professional use (e.g., royalties, stocks, stock options, or a decision-making position) from a commercial party related directly or indirectly to the subject of this manuscript.

DOI: 10.1097/01.BRS.0000020725.01916.7E duction, the ability of a material to promote bone growth by allowing bone formation on its surface, may suffice where sufficient quantities and margins of bone exist. In many cases, osteoinduction, defined as de novo bone formation at soft or hard tissue sites, offers clear advantages for biologic reconstruction. Alloplastic agents are at best osteoconductive, and may be viewed in many cases simply as bioinert void fillers. Allograft (mineralized or demineralized) provides an osteoconductive environment, and is widely believed to contain some osteoinductive capacity. However, its osteoinductive capacity is highly variable depending on the processing method and sourcing, and may in fact be present in inadequate amounts for any bone-inductive effect in humans. ${ }^{27,28}$

In some instances such as spinal fusion, the only successful grafting material is autograft. This material provides an osteoconductive environment coupled with cells as well as growth and differentiation factors that can result in osteoinduction. However, the available amounts of autograft, the morbidity associated with the graft harvest, and the variability in fusion success rate remain issues. The discovery and subsequent production of the osteoinductive agents in bone, the bone morphogenetic proteins (BMPs), have provided the possibility of replacing the need for autograft with a tissue-engineering product. In addition, the ability to control the quality, activity, and dose of an osteoinductive agent may provide greater assurance of bone induction and repair.

Several different osteoinductive BMP-containing materials are being evaluated currently in animal and clinical studies for their use as bone-inductive grafts. This article reviews the history of the discovery of the BMPs, and discusses the similarities and differences between the BMP materials in clinical use. The focus is on the biology of the BMPs themselves. Other articles in this volume more fully discuss important differences in the BMPcontaining graft materials. These include the nature of the matrix material used to deliver the BMP and the studies that support the safe and effective use of the material for clinical use.

\section{Discovery of the BMPs}

The ability of devitalized bone, when implanted in an animal, to induce a cellular response resulting in new bone tissue formation has been known for decades. ${ }^{35}$ This unique activity was observed and researched extensively by an orthopedic surgeon, Dr. Marshall Urist. He subsequently demonstrated that this activity could be extracted from the organic component of bone using chaotropic agents, and that a protein or proteins were responsible for this activity. ${ }^{36,37} \mathrm{He}$ thus named this ac- 


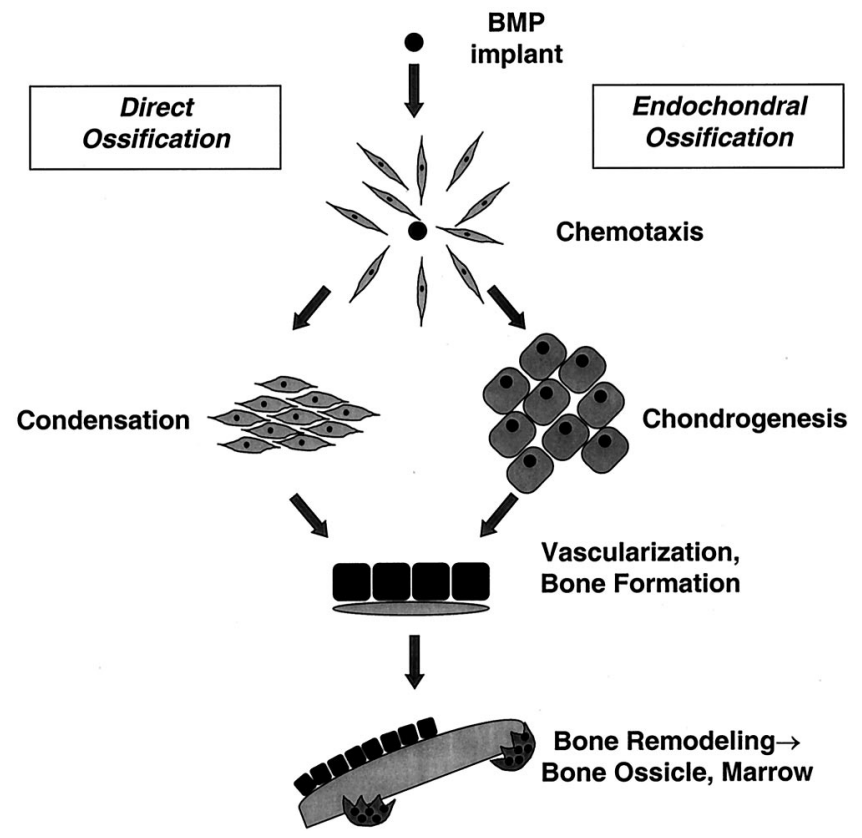

Figure 1. Cellular events after implantation of bone morphogenetic protein (BMP). These proteins induce both endochondral (through a cartilage intermediate) and direct (intramembranous) bone formation. The end result in each case is woven bone that then remodels and becomes populated with hematopoietic bone marrow.

tivity "bone morphogenetic protein." Implantation of this protein component of bone matrix resulted in a complex series of cellular events (Figure 1) including mesenchymal cell infiltration, cartilage formation, vascularization, bone formation, and ultimately remodeling of the new bone tissue along with population by hematopoietic bone marrow elements. ${ }^{24}$ Other tissue types including epithelium as well as bone cell lines were additionally observed to produce a similar bone-inductive activity. ${ }^{12,38,44}$

Bone matrix contains a variety of protein components, including an array of growth and differentiation factors. Thus, it remained elusive whether the observed BMP activity resulted from the combined activities of already identified factors, or was inherent to a new protein factor. Advances in biochemical techniques and the advent of biotechnology eventually allowed the purification and subsequent molecular cloning of the factors responsible for the osteoinductive activity in bone. ${ }^{40,46}$ With bovine bone used as a starting material, an extensive purification process was undertaken. Critical to the purification process was the use of an in vivo bioassay for bone induction. ${ }^{26}$ This assay involved combining column fractions with an inactivated collagenous bone matrix, followed by subcutaneous implantation in rats. The endpoint of the assay was the histologic observation of new cartilage and bone formation. Although this assay was labor intensive and time consuming, it was specific for the desired activity. Earlier attempts at purification using surrogate in vitro assay systems resulted in identification of previously known growth factors. 3,20,29
The purification process included removal of the mineral component of bone with acid, extraction of the active component from the remaining organic matrix of bone using chaotropic agents, and multiple column chromatography steps. Due to the insolubility of this extract, most of the column steps were performed with the material in guanidine or urea. Beginning with kilogram quantities of bone, microgram quantities of purified osteoinductive material eventually were obtained. Biochemical analysis indicated that despite the extensive purification, multiple proteins still were present. To determine which were responsible for bone inductive activity, each protein in this mixture was cloned molecularly and tested for in vivo activity. ${ }^{46}$

Using amino acid sequence information from this purified extract, the genes or cDNAs encoding each of the proteins were cloned molecularly. Analysis of these clones indicated that the bone-inductive extract consisted of a family of related proteins, which were named the "bone morphogenetic proteins," after the original activity. This family consists of the molecules BMP-2 through BMP-8, which are dimeric molecules belonging to the transforming growth factor- $\beta$ (TGF $\beta$ ) superfamily. ${ }^{4,21,22,46}$ The TGF $\beta$ family comprises a large number of growth and differentiation factors, which are related in primary amino acid sequence. All of these factors form dimeric molecules. Each subunit contains three intrachain disulfide bonds, and the subunits generally are held together with a fourth bond. Almost all members of the family, including the BMPs, are synthesized as precursor molecules, with the propeptide being clipped from the mature protein during secretion from the cell.

Comparisons among the derived amino acid sequences of the BMPs found in osteoinductive extracts of bone indicate that they fall into three subclasses (Figure 2). The first subclass contains BMP-2 and BMP-4, highly related molecules that differ mainly in the amino terminal region, with BMP-2 containing a heparin-binding domain. In the second subclass are BMP-5, BMP-6, and BMP-7, also known as osteogenic protein-1 (OP-1), and BMP-8 (OP-2). These are slightly larger proteins than BMP-2 and BMP-4, and there an approximate $70 \%$ amino acid identity between the subgroups. In the third subclass, and more distantly related to these factors, is BMP-3, also called osteogenin.

Proof that these proteins were responsible for the boneinductive activity in bone matrix was found in the recombinant expression of each of these proteins. By the use of molecular biology techniques and sequence information from the bovine molecular clones, the human homologs of each BMP coding sequence were obtained. Mammalian cells were engineered to express each protein by inserting the coding sequence (gene) for each protein into an expression vector and producing stable cell lines (see later discussion for the details on recombinant expression). Each cell line thus produces a single BMP molecule that is secreted into the medium wherein the cells are growing. The protein then can be tested by implantation in the in vivo bone induction assay system. Using this 


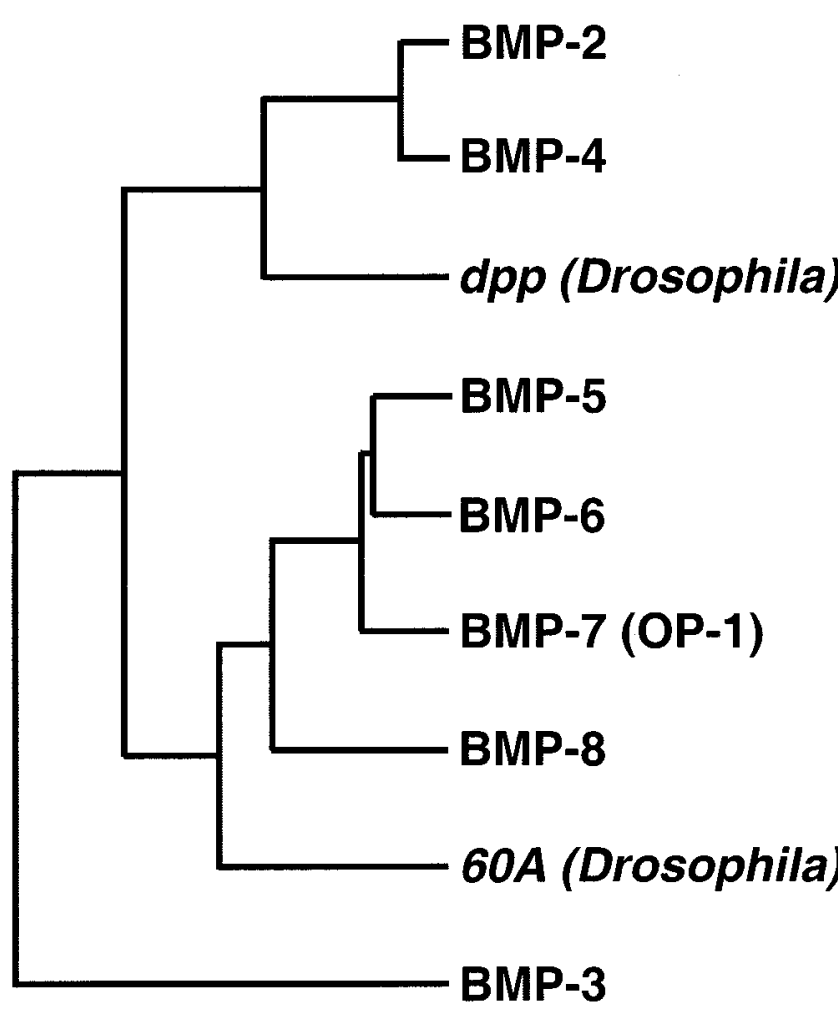

Figure 2. Interrelations of the bone morphogenetic protein (BMP) family members. The figure represents a "family tree" of the BMP genes based on sequence identity. One subgroup consists of human BMP-2, BMP-4, and Drosophila (fruit fly) decapentaplegic (dpp). A second subgroup comprises human BMP-5, BMP-6, BMP-7, BMP-8, and Drosophila 60A. Human BMP-3 is less related.

process, BMP-2 was first shown to induce the formation of new cartilage and bone tissues, demonstrating that members of this class of molecules were necessary and sufficient for osteoinduction. ${ }^{41}$ Subsequently, it was demonstrated that other BMP proteins also induce bone formation. ${ }^{8,25}$ It is interesting to note that although bone matrix contains a mixture of BMPs, implantation of an individual protein is sufficient for the entire osteoinductive process.

On the basis of sequence homology, the BMP family is now known to include a large number of members. In fact, it now constitutes the largest part of the TGF $\beta$ superfamily. The other molecules have been identified by a variety of methods, including sequence homology to the osteoinductive BMPs and genetic approaches. The nomenclature is complex including BMPs, growth and differentiation factors (GDFs), and others depending on the method used to identify them. These have been identified in a wide range of invertebrate and vertebrate species including worms, ${ }^{33}$ flies, ${ }^{23,42}$ frogs,${ }^{34}$ and of course, humans. In each of these species, BMPs play pivotal roles in embryonic developmental processes. For example, decapentaplegic, the fly ortholog of the mammalian BMP-2 and BMP-4 genes, is required at multiple stages of development including specification of the dorsal-ventral axis and formation of the appendages.
Clinical Use of BMPs as Osteoinductive Agents and Considerations for Their Use

Several preparations of BMPs are being evaluated preclinically and clinically for use in spinal fusion and for many other applications in which bone induction is desired. These BMP-based products include recombinant human bone morphogenetic protein-2 (rhBMP-2), rhBMP-7 or osteogenic protein-1 (OP-1), bovine bonederived BMP extract, and GDF-5. This first two are manufactured by a recombinant DNA biotechnology process using mammalian cells, and thus consist of single BMP molecules. The bovine BMP extract is purified from bone, and therefore contains a mixture of BMP molecules and other noncollagenous proteins derived from bone. Apparently, GDF-5 is manufactured by a recombinant DNA process using bacterial expression followed by in vitro refolding.

Both rhBMP-2 and rhBMP-7 are manufactured using mammalian cell expression. To generate a production cell line, the human BMP DNA coding sequence is placed in a vector system that contains appropriate promoterenhancer sequences and a selectable marker (e.g., Israel et $\left.\mathrm{al}^{13}\right)$. This vector is transfected into the mammalian cell host of choice, in this case Chinese hamster ovary $(\mathrm{CHO})$ cells, a common host cell line used in the biotechnology industry. Using the selectable marker, the BMP coding sequence is amplified until many copies reside in a chromosome of the cell. After characterization to ensure fidelity of expression, the cell line is expanded and frozen down into a cell bank. During the production process, an aliquot of the cell line is thawed and grown in sequentially larger volumes of culture medium. Eventually, fermentation tanks containing thousands of liters of the BMP-expressing cells in medium are obtained. The BMP then is purified from the conditioned medium. As mammalian cells are used to synthesize these BMPs, the molecules are dimerized, processed (i.e., by removal of the propeptide), and glycosylated (by the addition of sugar moieties), as are the naturally occurring molecules. The advantages of this recombinant production system include its reproducibility, ability to ensure the consistent purity and activity of the BMP, and ability to ensure freedom from adventitious agents.

Bone-derived BMPs are manufactured starting with bovine bone. The process presumably includes steps similar to those used in the original protein purification (see the article by Damien in this issue of Spine). These include removal of the fat and mineral component of bone, followed by extraction of BMPs from the bone matrix. The BMP extract then is purified using a series of chromatography steps. The resulting purified extract contains a mixture of BMP molecules, each of which may possess a slightly different activity as well as other contaminating proteins. Because it is known that the amount of BMPs present in bone is variable, control of the starting material (e.g., the age and size of the animals that provide the bone) is important. 
Several considerations are relevant to the selection of an optimal bone-inductive agent. The effectiveness of the product is dependent on the intrinsic activity of the agent (BMP) being applied, which is the aspect emphasized in this article. However, the activity is influenced by the method used to apply the BMP (i.e., procedures involving matrix or carrier material). As discussed elsewhere in this issue of Spine, the matrix imparts both biologic aspects (e.g., maintenance of the osteoinductive agent at the site of implantation, osteoconduction) and physical properties to the implanted material. Interestingly, the first BMP-based products to enter the clinical domain all use collagenous systems for delivery of the BMP. However, the materials differ in their physical nature (sponge vs particulate). Another important variable can be the dose or concentration of BMP in the product. As expanded on later, dose-ranging preclinical and clinical experiments are necessary to optimize the dose applied. In addition to the product's effectiveness, its safety must be considered. Aspects of the product that have an impact safety include purity, localized activity, systemic availability, immunogenicity, and biocompatibility.

The BMPs are intrinsically stable proteins, partly at least because of their tightly folded, disulfide bondstabilized structures. It should be noted that in the original purification process, BMP activity survived removal of the bone mineral component with hydrochloric acid, followed by months of processing in strongly chaotropic agents such as urea. The shelf life of the BMP-based products is based on biochemical and activity assays of materials placed on accelerated or real-time stability protocols. Although many of these protocols are still in progress, the stability of a material such as lyophilized rhBMP-2 appears to be on the order of years.

\section{Activities of the BMPs}

When implanted in vivo, the osteoinductive BMPs initiate a complex series of cellular events culminating in bone formation. For example, over a range of concentrations, rhBMP-2 results in endochondral bone formation including mesenchymal cell infiltration, differentiation of the cells into chondrocytes, removal of the cartilage, formation of bone, population of the bone with bone marrow elements, and ultimately normal remodeling of the bone (Figure 1). Thus, a single BMP molecule has the same activity as extracts of bone. The availability of pure, recombinant BMP proteins allowed analysis of the effect that implanting various doses (concentrations) of a BMP has on the rodent subcutaneous assay system. A steep dose-response curve is observed, with low doses resulting in small amounts of cartilage and bone formation. However, at no concentration is stable cartilage formation observed. The cartilage always is replaced by bone. ${ }^{41}$ Larger doses result in more substantial bone formation and earlier osteoinduction. Interestingly, when higher concentrations of BMPs are applied, bone forms at the same time as cartilage formation, suggesting that $\mathrm{BMP}$ can result in direct (intramembranous) ossification.
Table 1. Functional Analysis of BMP Genes

\begin{tabular}{|c|c|}
\hline BMP Gene & Phenotype of Null Mutation in Mice \\
\hline BMP- $2^{48}$ & $\begin{array}{l}\text { Lethal before formation of the skeleton. Defects in } \\
\text { amnion, chorion, and cardiac development. }\end{array}$ \\
\hline BMP $-4^{43}$ & $\begin{array}{l}\text { Early embryonic lethal with defects in } \\
\text { development of the mesoderm. }\end{array}$ \\
\hline BMP $-5^{16}$ & $\begin{array}{l}\text { Mouse short ear locus. Mice are viable with } \\
\text { defects in growth and patterning of skeletal } \\
\text { elements. Also have impaired fracture repair. }\end{array}$ \\
\hline BMP $-6^{30}$ & $\begin{array}{l}\text { Viable mice with skeletal elements } \\
\text { indistinguishable from wild type mice. Slight } \\
\text { delay in ossification of the sternum. }\end{array}$ \\
\hline BMP- $7^{15,} 17$ & $\begin{array}{l}\text { Perinatal lethal with defects in kidney and eye } \\
\text { development. Also patterning defects in ribs, } \\
\text { skull, and limbs. }\end{array}$ \\
\hline BMP- $8^{49-51}$ & $\begin{array}{l}\text { Duplicated genes (BMP8a and BMP8b) in mice; } \\
\text { no skeletal phenotype; defects in } \\
\text { spermatogenesis or placental development. }\end{array}$ \\
\hline BMP-3, 6 & $\begin{array}{l}\text { Viable with increased trabecular bone density. No } \\
\text { other skeletal phenotype. }\end{array}$ \\
\hline GDF-5 $5^{32}$ & $\begin{array}{l}\text { Mouse brachypodism locus. Alterations in number } \\
\text { and length of skeletal elements of the limbs; } \\
\text { joint formation defect. }\end{array}$ \\
\hline
\end{tabular}

Indeed, in some animal models, only direct bone formation is observed. The relative amounts of endochondral and intramembranous ossification induced appear to be associated with the concentration of BMP implanted, the site of implantation, and the nature of the carrier and matrix material.

When assayed in the rat system using inactivated demineralized bone matrix as a carrier, several of the BMPs appear to have indistinguishable activities, including BMP-2, BMP-7 (OP-1), and BMP-6. ${ }^{8,25,41}$ These all result in similar cellular events, culminating in bone induction, and similar amounts result in similar amounts of bone. Other BMPs, such as BMP-5, require higher doses for similar amounts of osteoinduction. ${ }^{5}$ The most abundant BMP in bone, BMP-3 (osteogenin), appears to be inactive in this assay system, and may even be a negative modulator of bone formation. ${ }^{1,6}$ The more distantly related molecule, GDF-5, is osteoinductive only at much higher amounts. ${ }^{31}$ In addition, members of this subfamily of molecules have been implicated in tendon and ligament formation. ${ }^{45}$

The physiologic roles of the BMPs include pivotal roles during embryonic development in the specification of positional information in the embryo and the requirement for skeletal and nonskeletal tissue formation. ${ }^{10,18}$ Analysis of gene knockouts (Table 1), ${ }^{16,30,43,48-51}$ in which one or more BMP genes are inactivated, indicate that there is some redundancy in the BMP family. However, each appears to have a unique role in the formation of one or more tissue types. For example, elimination of the BMP-7 gene results in developmental abnormalities of the kidney and eye, with skeletal deficits. ${ }^{15,17}$ Inactivation of GDF-5 results in deficits in only specific skeletal elements. ${ }^{32}$ Because BMP-2 and BMP-4 are required much earlier in embryonic development, their roles in skeletal development remains unknown. Whether these 
divergent observations can be extrapolated to describe their activities in the adult animal is less clear.

That BMP-2 and BMP-7 have similar osteoinductive activities in vivo is perhaps not surprising given that they share similar overlapping sets of cellular receptors. Both signal through the heteromeric "BMP" receptor complex, which comprises one of two Type 1 receptor subunits and a Type 2 BMP receptor subunit. However, BMP-7 also has been reported to signal through the activin receptor complex, and thus to possess some activinlike activities. ${ }^{47}$ Although these two BMPs appear to have similar effects at the cellular level, extrapolation of this observation to the in vivo situation is complicated. For example, localized bone induction likely is controlled through a series of negative regulatory feedback loops, including induction of extracellular inhibitors of BMP action by the BMPs themselves. Whether individual BMPs have similar effects on these systems is not known. Similarly, the systemic clearance rate of the BMP can affect its local efficacy and systemic activity and safety. Although both molecules appear to have rapid initial clearance, BMP-7 has been reported to have an extended terminal half-life resulting in low circulating levels of the protein. ${ }^{7}$ In addition, BMP-7 has been reported to have effects on the kidney during systemic administration, ${ }^{2,11,39}$ whereas no systemic effects have been found for BMP-2 (see the article by Lane et al in this issue of Spine).

Because the BMPs are dimeric molecules, it is possible to form heteromeric BMPs. For example, one dimer might consist of a BMP-2 subunit and a BMP-7 subunit. Given the number of BMP genes known, the possible number of combinations is large. Recombinant expression and subsequent purification of heterodimers is difficult because cells must be engineered to express similar levels of both subunits. In addition, because of the biochemical similarity between the homo- and heterodimers, purification is problematic. In spite of these obstacles, it has been shown that some heterodimeric BMPs have higher specific activities than their homodimeric counterparts. ${ }^{14}$ For example, implanting $10 \%$ of a heterodimer quantity can result in the same amount of bone formation as with the homodimer in the rat ectopic system. However, no qualitative difference in the way bone is formed or in the quality of the bone induced can be discerned. In retrospect, bone matrix likely contains a mixture of heterodimeric and homodimeric BMPs, each with its unique specific activity. Thus, bovine BMP extract is likely to contain many of these BMPs. Although it is difficult to evaluate the relative levels of each in bone or bone extracts because of technical limitations, it is possible that individual BMPs, such as BMP-2 and BMP-7, may be present at only one part per billion of mineralized bone.

It is perhaps surprising that such a large family of BMPs exists, and indeed that many osteoinductive BMPs are present in bone matrix. The BMPs are key players in embryonic development, and each appears to have a unique role in this process from the earliest events through development of the tissues to patterning of the skeletal system. According to information gathered from the gene knockout experiments, clearly some redundancy exists in the BMP genes' roles in development. This may have been selected for on the basis of their pivotal roles. Whether similar redundancy is functionally necessary in the adult organism or whether the presence of many BMPs in the adult is a legacy of their presence during development remains unknown.

\section{Perspective}

Tissue engineering with bioactive factors is likely to transform the bone-grafting procedures currently used in orthopedic surgery. The BMPs set themselves apart from other bioactive factors by their mechanism of action at the cellular level. The BMPs are differentiation factors, causing mesenchymal cells to differentiate (mature) into bone- and cartilage-forming cells.

In contrast, factors such as platelet-derived growth factor (PDGF) and TGF $\beta$ are growth factors. Growth factors cause cells to divide, thus expanding their numbers, and may cause cells to augment production of cellular products such as extracellular matrix proteins. As such, preparations such as platelet rich plasma (a major source of PDGF and TGF $\beta$ ) may be used to enhance bone graft. It is important to note that combining BMPs with growth factors involves no synergistic or additive effect. In fact, the body of information suggests that these classes of factors may antagonize one another's activity. ${ }^{9,19}$ Other tissue engineering products used in bone and cartilage repair may contain autogenous cells, which are harvested from the host, expanded ex vivo, and then reimplanted. In contrast to the use of growth factor preparations and cell-based therapies, the BMPs offer the unique opportunity to replace the use of autogenous bone graft with an off-the-shelf material containing the $\mathrm{BMP}$ and an inert carrier system. As differentiation factors, they cause the host (patient) to induce the formation of their own bone, which functions and remodels in a manner appropriate for the anatomic site and biomechanic environment in which it resides. Although application of a single BMP can induce this complex cellular response, it is likely that it involves expression of multiple BMPs and various growth factors in a specific temporal sequence to complete the process of bone formation.

Several BMP-based products may be available for clinical use by the orthopedic surgeon. Recombinant expression, used in the production of rhBMP-2 and rhBMP-7, provides advantages in terms of providing well-characterized osteoinductive proteins with consistent high purity and activity while ensuring the absence of adventitious agents. On the other hand, the bonederived mixture of BMPs in bovine BMP extract may contain molecules with higher specific activities than either homodimer. However, although direct comparisons have not been performed, it appears that similar quanti- 
ties of this bone extract are necessary to promote bone induction. It appears that GDF-5 has substantially reduced osteoinductive activity. Hence adjustments may need to be made to the dose or delivery system for its successful use as a replacement for autograft.

Although each of these biologic agents is osteoinductive in vivo, other elements are required for their successful use as bone grafting materials. For the product to be effective, the amount (dose) requirements for the BMP must be carefully studied, understood, and proved in preclinical and clinical studies. The matrix or carrier material modulates the biologic response to the osteoinductive protein by controlling its retention time, providing a region for the bone formation process to occur, and localizing its activity. Thus, selection of the matrix is important. Again, it must be studied carefully in animal models. Equally important is assurance of the product's safety. The safety of the protein and the protein in combination with its matrix material should be carefully evaluated in relevant animal models. The results of these studies, where available, are discussed in subsequent articles in this issue of Spine.

\section{- Key Points}

- Bone morphogenetic proteins comprise the osteoinductive component of several tissue engineering products in late-stage development as replacements for autogenous bone graft, and for bone augmentation and repair.

- Successful development of a product for use in spinal fusion involves selecting the osteoinductive molecule, the amount of the bone morphogenetic protein required, and the method of delivery, as well as conducting subsequent preclinical and clinical studies to evaluate its efficacy and safety.

- Some of these bone morphogenetic proteinbased products provide for revolutionary therapies in orthopedic practice.

\section{References}

1. Bahamonde ME, Lyons KM. BMP3: To be or not to be a BMP. J Bone Joint Surg [Am] 1901;83(Suppl 1):S56-62.

2. Bosukonda D, Shih MS, Sampath KT, et al. Characterization of receptors for osteogenic protein-1/bone morphogenetic protein-7 (OP-1/BMP-7) in rat kidneys. Kidney Int 2000;58:1902-11.

3. Canalis E, McCarthy T, Centrella M. A bone-derived growth factor isolated from rat calvariae is beta-2 microglobulin. Endocrinology 1987;121:1198200 .

4. Celeste AJ, Iannazzi JA, Taylor RC, et al. Identification of transforming growth factor- $\beta$ family members present in bone-inductive protein purified from bovine bone. Proc Natl Acad Sci U S A 1990;87:9843-7.

5. D'Alessandro JS, Cox KA, Israel DI, et al. Purification, characterization, and activities of recombinant bone morphogenetic protein 5. J Bone Miner Res 1991;6:S153.

6. Daluiski A, Engstrand T, Bahamonde ME, et al. Bone morphogenetic protein-3 is a negative regulator of bone density. Nat Genet 2001;27:84-8.

7. Committee for Proprietary Medicinal Products. Osteogenic Protein 1 Howmedica International S.DE.R.L. In: European Public Assessment Report. London: The European Agency for the Evaluation of Medicinal Products, 2000 .

8. Gitelman SE, Kobrin MS, Ye J-Q, et al. Recombinant Vgr-1/BMP-6- expressing tumors induce fibrosis and endochondral bone formation in vivo. J Cell Biol 1994;126:1595-609.

9. Harris SE, Bonewald LF, Harris MA, et al. Effects of transforming growth factor- $\beta$ on bone nodule formation and expression of bone morphogenetic protein 2, osteocalcin, osteopontin, alkaline phosphatase, and type I collagen mRNA in long-term cultures of fetal rat calvarial osteoblasts. J Bone Miner Res 1994;9:855-63.

10. Hogan BLM. Bone morphogenetic proteins: Multifunctional regulators of vertebrate development. Genes Dev 1996;10:1580-94.

11. Hruska KA, Guo G, Wozniak M, et al. Osteogenic protein-1 prevents renal fibrogenesis associated with ureteral obstruction. Am. J Physiol Renal Physiol 2000;279:F130-43.

12. Huggins $\mathrm{CB}$. The formation of bone under the influence of epithelium of the urinary tract. Arch Surg 1931;22:377-408.

13. Israel DI, Nove J, Kerns KM, et al. Expression and characterization of bone morphogenetic protein-2 in Chinese hamster ovary cells. Growth Factors 1992;7:139-50.

14. Israel DI, Nove J, Kerns KM, et al. Heterodimeric bone morphogenetic proteins show enhanced activity in vitro and in vivo. Growth Factors 1996; 13:291-300.

15. Jena N, Martin-Seisdedos C, McCue P, et al. BMP7 null mutation in mice: Developmental defects in skeleton, kidney, and eye. Exp Cell Res 1997;230 28-37.

16. Kingsley DM, Bland AE, Grubber JM, et al. The mouse short ear skeletal morphogenesis locus is associated with defects in a bone morphogenetic member of the TGF $\beta$ superfamily. Cell 1992;71:399-410.

17. Luo G, Hofmann C, Bronckers ALJJ, et al. BMP-7 is an inducer of nephrogenesis, and is also required for eye development and skeletal patterning. Genes Dev 1995;9:2808-20.

18. Lyons KM, Jones CM, Hogan BLM. The DVR gene family in embryonic development. Trends Genet 1991;7:408-12.

19. Marden LJ, Fan RSP, Pierce GF, et al. Platelet-derived growth factor inhibits bone regeneration induced by osteogenin, a bone morphogenetic protein, in rat craniotomy defects. J Clin Invest 1993;92:2897-905.

20. Mohan S, Jennings JC, Linkhart TA, et al. Primary structure of human skeletal growth factor: Homology with human insulin-like growth factor-II. Biochim Biophys Acta 1988;966:44-55.

21. Özkaynak E, Rueger DC, Drier EA, et al. OP-1 cDNA encodes an osteogenic protein in the TGF- $\beta$ family. EMBO J 1990;9:2085-93.

22. Özkaynak E, Schnegelsberg PNJ, Jin DF, et al. Osteogenic protein-2: A new member of the transforming growth factor- $\beta$ superfamily expressed early in embryogenesis. J Biol Chem 1992;267:25220-7.

23. Padgett RW, St. Johnston RD, Gelbart WM. A transcript from a Drosophila pattern gene predicts a protein homologous to the transforming growth factor- $\beta$ family. Nature 1987;325:81-4.

24. Reddi AH. Cell biology and biochemistry of endochondral bone development. Collagen Rel Res 1981;1:209-26.

25. Sampath TK, Maliakal JC, Hauschka PV, et al. Recombinant human osteogenic protein-1 (hOP-1) induces new bone formation in vivo with a specific activity comparable with natural bovine osteogenic protein and stimulates osteoblast proliferation and differentiation in vitro. J Biol Chem 1992;267: 20352-62.

26. Sampath TK, Reddi AH. Dissociative extraction and reconstitution of extracellular matrix components involved in local bone differentiation. Proc Natl Acad Sci U S A 1981;78:7599-603.

27. Schwartz Z, Mellonig JT, Carnes DL, Jr, et al. Ability of commercial demineralized freeze-dried bone allograft to induce new bone formation. J Periodontol 1996;67:918-26.

28. Schwartz Z, Somers A, Mellonig JT, et al. Ability of commercial demineralized freeze-dried bone allograft to induce new bone formation is dependent on donor age but not gender. J Periodontol 1998;69:470-8.

29. Seyedin SM, Thompson AY, Bentz H, et al. Cartilage-inducing factor-A: Apparent identity to transforming growth factor- $\beta$. J Biol Chem 1986;261: 5693-5.

30. Solloway MJ, Dudley AT, Bikoff EK, et al. Mice lacking BMP-6 function. Dev Genet 1998;22:321-39.

31. Spiro RC, Liu L, Heidaran MA, et al. Inductive activity of recombinant human growth and differentiation factor-5. Biochem Soc Trans 2000;28: 362-8.

32. Storm EE, Huynh TV, Copeland NG, et al. Limb alterations in brachypodism mice due to mutations in a new member of the TGF $\beta$ superfamily. Nature 1994;368:639-43.

33. Suzuki Y, Yandell, MD, Roy PJ, et al. A BMP homolog acts as a dosedependent regulator of body size and male tail patterning in Caenorhabditis elegans. Development 1999;126:241-50.

34. Ueno N, Shoda A, Takebayashi K, et al. Identification of bone morphoge- 
netic protein-2 in early Xenopus laevis embryos. Growth Factors 1992;7: $233-40$.

35. Urist MR. Bone: Formation by autoinduction. Science 1965;150:893-9.

36. Urist MR, Iwata H, Ceccotti PL, et al. Bone morphogenesis in implants of insoluble bone gelatin. Proc Natl Acad Sci U S A 1973;70:3511-15.

37. Urist MR, Mikulski A, Lietze A. Solubilized and insolubilized bone morphogenetic protein. Proc Natl Acad Sci U S A 1979;76:1828-32.

38. Urist MR, Nakata N, Felser JM, et al. An osteosarcoma cell and matrix retained morphogen for normal bone formation. Clin Orthop 1977;124: 251-66.

39. Vukicevic S, Basic V, Rogic D, et al. Osteogenic protein-1 (bone morphogenetic protein-7) reduces severity of injury after ischemic acute renal failure in rat. J Clin Invest 1998;102:202-14.

40. Wang EA, Rosen V, Cordes P, et al. Purification and characterization of other distinct bone-inducing factors. Proc Natl Acad Sci U S A 1988;85: 9484-8.

41. Wang EA, Rosen V, D'Alessandro JS, et al. Recombinant human bone morphogenetic protein induces bone formation. Proc Natl Acad Sci U S A 1990; $87: 2220-4$

42. Wharton KA, Thomsen GH, Gelbart WM. Drosophila 60A gene, another transforming growth factor $\beta$ family member, is closely related to human bone morphogenetic proteins. Proc Natl Acad Sci U S A 1991;88:9214-18.

43. Winnier G, Blessing M, Labosky PA, et al. Bone morphogenetic protein-4 is required for mesoderm formation and patterning in the mouse. Genes Dev 1995;9:2105-16

44. Wlodarski K. The inductive properties of epithelial established cell lines. Exp Cell Res 1969;57:446-8.

45. Wolfman NM, Hattersley G, Cox K, et al. Ectopic induction of tendon and ligament in rats by growth and differentiation factors 5,6 , and 7 , members of the TGF- $\beta$ gene family. J Clin Invest 1997;100:321-30.
46. Wozney JM, Rosen V, Celeste AJ, et al. Novel regulators of bone formation: Molecular clones and activities. Science 1988;242:1528-34.

47. Yamashita H, ten Dijke P, Huylebroeck D, et al. Osteogenic protein-1 binds to activin type II receptors and induces certain activin-like effects. J Cell Biol $1995 ; 130: 217-26$.

48. Zhang HB, Bradley A. Mice deficient for BMP2 are nonviable and have defects in amnion/chorion and cardiac development. Development 1996; 122:2977-86

49. Zhao GQ, Deng K, Labosky PA, et al. The gene encoding bone morphogenetic protein $8 \mathrm{~B}$ is required for the initiation and maintenance of spermatogenesis in the mouse. Genes Dev 1996;10:1657-69.

50. Zhao GQ, Hogan BLM. Evidence that mouse $B m p 8 a(\mathrm{O} p 2)$ and $B m p 8 b$ are duplicated genes that play a role in spermatogenesis and placental development. Mech Develop 1996;57:159-68.

51. Zhao GQ, Liaw L, Hogan BLM. Bone morphogenetic protein 8 A plays a role in the maintenance of spermatogenesis and the integrity of the epididymis. Development 1998;125:1103-12.

Address reprint requests to

John M. Wozney, PhD

Wyeth Research

87 CambridgePark Drive

Cambridge, MA 02140

E-mail:jwozney@wyeth.com 